\title{
Dry up and survive: the role of antioxidant defences in anhydrobiotic organisms
}

\author{
Lorena REBECCHI*
}

Department of Life Sciences, University of Modena and Reggio Emilia, Via G. Campi 213/D, 41125 Modena, Italy

*Corresponding author: lorena.rebecchi@unimore.it

\begin{abstract}
Although the evolution of life has turned oxygen into a vital chemical for aerobic organisms, this element can also have deleterious effects on living systems through the production of oxidative stress. This is a process resulting from an imbalance between the excessive production of Reactive Oxygen Species (ROS) and the limited action of antioxidant defences. It is a particularly harmful health risk factor, involved in the development of several chronic human pathologies and believed to play a major role in the ageing process. Consequently aerobic metabolism needs a stringent control of ROS. Water too is essential for life, but some organisms widespread throughout nature have the ability to survive complete desiccation by entering an anhydrobiotic state. The loss of water induces changes in metabolism, cell membrane organization, and molecular composition. In the anhydrobiotic state, high temperatures, high humidity, light exposure, and high oxygen partial pressure negatively affect organism survival and directly influence the time required to reactivate the metabolism after a period of desiccation. These abiotic factors induce damages that are accumulated in proportion to the time spent in the desiccated state, potentially leading to organism death. Oxidative stress seems to be one of the most deleterious damages due to water depletion, therefore anhydrobiosis also needs a stringent control of ROS production. Anhydrobiotic organisms seem to apply two main strategies to cope with the danger of oxygen toxicity, namely an increased efficiency of antioxidant defences and a metabolic control of both energy-production and energy-consuming processes. Experimental studies provide evidence that antioxidant defences such as ROS scavenging enzymes (e.g. peroxidases, catalases, superoxide dismutase, glutathione peroxidases) and other molecules (e.g. glutathione, carotenoids, vitamins $C$ and E) represent a key group of molecules required for desiccation tolerance in anhydrobiotic organisms. The action of these molecules emphasises the need for redox balancing in anhydrobiotic organisms including tardigrades and chironomid larvae.
\end{abstract}

Key words: anhydrobiosis, desiccation tolerance, adaptation, oxidative stress, reactive oxygen species, tardigrades, review.

\section{INTRODUCTION}

Since water is essential for life, its depletion leads to deleterious effects on organisms. A partial loss of water produces symptoms of dehydration, while complete water loss can lead to death for most organisms. For instance, humans die after a loss of $14 \%$ of their body water, and most organisms die when they lose $50 \%$ of their water at the body, organ, tissue, or cell level (Watanabe, 2006). However, many organisms have evolved adaptive strategies to withstand water loss, and these can be subdivided into two categories, namely desiccation avoidance and desiccation tolerance (Alpert, 2005, 2006; Cornette and Kikawada, 2011).

Organisms using desiccation avoidance strategy are able to maintain water uptake and/or minimize water loss from their body through ecological, physiological, morphological, and biochemical adaptations. Some true terrestrial arthropods are able to maintain their body water by having a low-permeable cuticle and locally specialized tissues able to absorb water from the atmosphere. In contrast, the tegument of the springtail Folsomia candida Willem, 1902 is highly permeable to water, so this collembolan needs to maintain its hyperosmotic body fluid by accumulating a high amount of glucose and myoinositol to allow net water uptake from the atmosphere by passive diffusion (Bayley and Holmstrup, 1999). This strategy allows the organism to maintain the appropriate amount of water under prolonged drought stress.

With the desiccation tolerance strategy, organisms have the ability to dry to an equilibrium state with the surrounding air, which could be from moderately to extremely dry (Alpert, 2005). Desiccation tolerance is not the same thing as drought tolerance, even though desiccation tolerance is one mechanism of drought tolerance. According to Alpert (2005), drought is related to the presence of the low amount of water in the surrounding environment of an organism, while desiccation is related to the low amount of water within the cells of an organism. Many organisms are able to tolerate drought, but die if they undergo complete desiccation. Drought tolerance is possible thanks to the evolution of different adaptive strategies. For example, in desert habitats, cactus accumulates water, while rodents synthesize water (Alpert, 2005).

Organisms using the desiccation tolerance strategy can be completely or partially tolerant to desiccation. From a functional point of view, partial desiccation tolerant organisms are able to maintain some amount of water as well as a certain degree of metabolism (Danks, 2000). For instance, while seeds that belong to the complete desiccation group are able to survive a loss of water more than $93 \%$ of their water content, seeds that belong to the partial 
desiccation group are unable to survive a loss of water higher than $80 \%$ (Tweddle et al., 2003). In any case, it is not clear whether there is a continuum between complete and partial desiccation tolerant organisms. A possible quantitative definition of complete desiccation is drying to less than $0.1 \mathrm{~g} \mathrm{H}_{2} \mathrm{O} \mathrm{g}^{-1}$ dry mass ( $10 \%$ water content) or less (Alpert, 2005). The threshold of $10 \%$ water content may correspond to the point at which there is not enough water to form a monolayer around macromolecules, which will then lead to the arrest of biochemical reactions and metabolism (Billi and Potts, 2002). With this strategy, organisms are able to suspend animation, cease metabolism to immeasurable levels, and retain normal biological functions after rehydration. Complete desiccation tolerance is therefore fundamentally different from partial desiccation tolerance.

To avoid confusion between complete and partial desiccation tolerance strategies, Keilin (1959) reintroduced the term anhydrobiosis (life without water). This word was used for the first time by Giard in 1895, and it can be considered a synonym of complete desiccation tolerance. Today it is the most commonly used term to indicate complete desiccation tolerance in the literature. As biochemical reactions occur only in the presence of water, an organism in the anhydrobiotic state lacks all visible dynamic features of living due to the absence of metabolism. In that sense it is not alive, but still not dead since rehydration reactivates the organism's metabolism. Thus, since the suspension of metabolism is reversible, anhydrobionts show a kind of repeated resurrection (Tunnacliffe and Lapinski, 2003).

To withstand the deleterious effects caused by the drastic loss of water, anhydrobiotic organisms evolved morphological, physiological and molecular/biochemical adaptations. Nevertheless, the molecular damages that negatively influence the survival of anhydrobiotic organisms, as well as the biochemical and molecular mechanisms involved in the complete desiccation tolerance strategy are currently little known and constitute an intriguing challenge for biologists. Consequently, this review focuses on the production of Reactive Oxygen Species (ROS) during the anhydrobiotic process and on the role of the antioxidant defences to counteract oxidative stress.

\section{SYNOPSIS OF ANHYDROBIOSIS}

Anhydrobiosis was documented for the first time in 1702 by van Leeuwenhoek. This Dutch scientist observed the recovery of living animalcules, namely bdelloid rotifers, from dry sediment collected in the gutter of his roof. Today, anhydrobionts are known for many taxa ranging from unicellular to multicellular organisms, including bacteria, yeast, fungal spores, plants, protozoans, and metazoans (Crowe et al., 1992; Clegg, 2001; Alpert, 2005,
2006). Among plants, anhydrobiosis is common in bryophytes, while it is rare in pteridophytes and angiosperms (Oliver et al., 2000). Nevertheless, in angiosperms anhydrobiosis is found in seeds and pollen and in the so called resurrection plants (Clegg, 2001; Tweddle et al., 2003; Illing et al., 2005).

Even though anhydrobiosis has great adaptive potential, in animals it can be found only in a restricted number of invertebrate taxa whose body size does not exceed 5-7 $\mathrm{mm}$ in length, and often they are much smaller (Alpert, 2005). However, no anhydrobiotic vertebrate species have been found due to physiological constraints. Among metazoans, anhydrobiosis is very common in several species of terrestrial and phytopathogenic nematodes, bdelloid rotifers, and in semiterrestrial heterotardigrades and eutardigrades (Càceres, 1997; Clegg, 2001; Ricci, 2001; Watanabe, 2006; Rebecchi et al., 2007). For instance, although tardigrades colonise a wide range of ecosystems all over the world, the highest number of species is found in terrestrial habitats subjected to stochastic desiccation and rehydration (e.g. lichens, mosses, leaf litter, and turfs) that preclude most other animals. In these habitats, tardigrades being aquatic animals are able to perform all activities of routine life (i.e. eat, grow, reproduce) only when surrounded by at least a film of liquid water. Mosses, lichens and lawn grass provide habitats featuring a myriad of small pockets of water. As their surroundings lose water, the tardigrades also lose their body water and enter into the anhydrobiotic state. When environmental conditions change and water returns, active life begins again. Consequently, seasonal and daily variations in water availability have a great impact on the tardigrade life cycle, which consists of active periods for growth and reproduction, interrupted by periods of metabolic inactivity.

Holo-anhydrobiotic animals such as tardigrades, rotifers and nematodes have the ability to enter anhydrobiosis at any stage of their life cycle, from egg to adult, even though anhydrobiotic species differ in their ability to withstand desiccation (Ricci, 1998; Jönsson et al., 2001; Jönsson, 2005; Faurby et al., 2008). In other animal taxa anhydrobiosis is restricted to the egg or juvenile stages of the life cycle. Typical examples are represented by the encysted embryos of branchiopod and ostracod crustaceans and larvae of the African sleeping chironomid Polypedilum vanderplanki Hinton, 1951 (Clegg, 2001, 2005; Watanabe, 2006; Rebecchi et al., 2007). It is remarkable that all these taxa inhabit ephemeral water ponds.

It is well known that anhydrobiosis confers cross-tolerance to various physical and chemical extremes including very low and high temperature, high pressure, vacuum, organic solvents, and ionizing and UV radiation (Mattimore and Battista, 1996; Billi et al., 2000; Rebecchi et al., 2007, 2009a, 2011; Watanabe et al., 2007; Gladyshev and Meselson, 2008; Hengherr et al., 2009a, b; Horikawa et al., 2009; Jönsson et al., 2008; Gusev et 
al., 2010; Nilsson et al., 2010; Altiero et al., 2011). Anhydrobiotic organisms are able to persist in a complete desiccated state from months to decades, or even centuries in seeds (Clegg, 2001; Alpert, 2005; Watanabe, 2006; Rebecchi et al., 2007; Møbjerg et al., 2011). In addition, anhydrobiosis does not seem to have effects on animal longevity/senescence, at least in rotifers and tardigrades (Ricci and Caprioli, 2005; Hengherr et al., 2008). Nevertheless, the survival of desiccated animals decreases in proportion to the dehydration rate and time spent in a desiccated state, leading to animal death (Rebecchi et al., 2006). High temperatures, high relative humidity, high oxygen partial pressure, and light exposure are responsible for the decrease of long-term anhydrobiotic survival as these abiotic factors induce damages that are accumulated in proportion to the time spent in the desiccated state (Neumann et al., 2009; Rebecchi et al., 2009b; Gusev et al., 2010). These abiotic conditions also directly influence the time required by animals to recover active life after a period of desiccation. However, long-term survival of desiccated organisms increases if they are stored under a vacuum and at very low temperatures (e.g. -20 or $\left.-80^{\circ} \mathrm{C}\right)$.

\section{OXIDATIVE STRESS AND ANHYDROBIOSIS}

The evolution of life has turned oxygen into a vital chemical for respiration in aerobic organisms. Nevertheless, this element can also have deleterious effects on living systems as it is a highly oxidizing molecule involved in the production of free radicals that induce oxidative stress (Kranner and Birtić, 2005; França et al., 2007; Eruslanov and Kusmartsev, 2010). For example, during respiration, mitochondria convert about $1-2 \%$ of the oxygen consumed into free radicals (Boveris and Chance, 1973).

Oxidative stress is a process resulting from an imbalance between the excessive production of ROS and the limited action of antioxidant defences (França et al., 2007). Among ROS there are the free radicals of oxygen [e.g. singlet oxygen $\left({ }^{1} \mathrm{O}_{2}\right)$, superoxide $\left(\mathrm{O}^{-}\right)$, hydroxyl radical $(\bullet \mathrm{OH})]$, which are atoms or molecules with an unpaired electron that can be rapidly donated making them highly reactive molecular species. Hydrogen peroxide $\left(\mathrm{H}_{2} \mathrm{O}_{2}\right)$ is not a free radical but it belongs to ROS, and it is capable of producing oxidative stress.

Reactive oxygen species produce significant cellular stress from bacteria to humans such as denaturation of proteins and enzymes, damage to nucleic acids, and peroxidation of lipid (Hansen et al., 2006). In addition, ROS are implicated in the development of many important chronic human pathologies (e.g. Parkinson and Alzheimer diseases, atherosclerosis, hypertension, ischemia, diabetes, cancer) and play a major role in the ageing process (Willcox et al., 2004). In contrast, in vascular plants, extracellular ROS production plays a defensive role against pathogenic bacteria and fungi at the site of infection (Wojtasezek, 1997).

Besides aerobic metabolism, several stresses are able to produce ROS. Oxidative stress seems to be one of the most deleterious effects of water depletion. For example, after dehydration the cells of yeast Saccharomyces cerevisiae Meyen ex E.C. exhibit an increase in oxidation that is 10-fold higher than that of hydrated cells (Pereira et al., 2003). Desiccated cyanobacteria contain high amounts of free radicals that are accumulated during dehydration, especially in the presence of light (Potts, 1994; Smirnoff, 1993). In the moss Fontinalis antipyretica L. ex Hedw., the production of ROS is associated with the dehydration rate. Low levels of ROS were detected in leaves dehydrated very slowly, whereas significantly higher values were found in leaves rapidly dehydrated (Cruz de Carvalho et al., 2012). In plants, the formation of ROS occurs also during drought and chilling (Price et al., 1989). As cellular water content decreases, the production of ROS causes damage to molecules among which lipid peroxidation. Lipid peroxidation produces a decrease in the fluidity of biological membranes and their fusion, which interferes with membrane permeability during rehydration (França et al., 2007; Cornette and Kikawada, 2011).

Even though the origin of ROS in anhydrobiosis is not yet well known, their production can occur both during the dehydration (entrance phase) and desiccated state. In particular, in the dehydration phase a large amount of ROS is more likely to be produced by the dysfunction of enzymatic reactions, while during the desiccated state, their production most probably occurs both through nonenzymatic reactions and auto-oxidations rather than through enzymatic reactions (Kranner and Birtić, 2005). Nevertheless, the possibility that enzymatic reactions occur during the desiccated state cannot be completely excluded (Kranner and Birtić, 2005). If a cell is desiccated until its cytoplasm enters a glassy state, a significant decrease in molecular mobility and in the rate of chemical reactions occurs. However, a glassy cytoplasm is still in the liquid phase and chemical reactions can take place, even though at a very low rate (Sun and Leopold, 1997). Under normal conditions, antioxidant systems minimize the adverse effects caused by ROS, but desiccation stress ultimately causes the loss of the control mechanisms that maintain low ROS levels. When the antioxidant defences of an organism fail during desiccation, oxidative stress prevails, limiting organism survival and longevity, and eventually leading to its death.

\section{ANTIOXIDANT DEFENCES AND ANHYDROBIOSIS}

The ability to survive desiccation involves a complex array of factors working at morphological, physiological, and molecular/biochemical levels. In bdelloid rotifers and 
tardigrades, the formation of a very body compact structure (the so-called tun; Fig. 1), is of crucial importance. Tun formation reduces body surface area and cuticular permeability, decreasing water evaporation and thus making desiccation a very slow process (Crowe, 1972, 1975; Wright, 1988, 1989a, 1989b; Rebecchi et al., 2007; Marotta et al., 2010).

A low desiccation rate allows organisms entering anhydrobiosis to synthesize different kinds of molecules working as bioprotectants. Some molecules (e.g. trehalose, sucrose) can work during the dehydration/entering phase, stabilising the biological membrane and avoiding protein unfolding and membrane disturbances. Others can work during the rehydration/leaving phase as chaperone systems (e.g. late embryogenesis abundant proteins, heat shock proteins, enzymes) repairing or eliminating damaged molecules, while others (e.g. antioxidant molecules) can work during all three phases of the anhydrobiotic process (i.e. entering, permanent, and leaving phases), counteracting the effects of ROS (Goyal et al., 2005; França et al., 2007; Rebecchi et al., 2007; Haegeman et al., 2009; Cornette et al., 2010; Schill, 2010; Guidetti et al., 2011; Wełnicz et al., 2011).

Anhydrobionts seem to apply two main strategies to cope with the danger of oxygen toxicity, namely a metabolic control of both energy-producing and energy-consuming processes and an increased efficiency of antioxidant defences (Wright, 2001; Kranner and Birtić, 2005; França et al., 2007). The very low or null metabolism of anhydrobionts limits the production/accumulation of by-products of metabolism such as free radicals. However, an effective, efficient antioxidant machinery is necessary as the formation of ROS occurs (see ahead).

\section{Antioxidants}

The antioxidant defences are represented by intra- and extracellular molecules that can be divided into primary and secondary defence mechanisms. Components of the primary group prevent oxidative damage directly by intercepting ROS before they can damage molecules. Components of the second group are represented by a number of repair enzymes (Rizzo et al., 2007; Eruslanov and Kusmartsev, 2010). In addition, classical antioxidants found in biological systems can be divided into water- or lipidsoluble molecules. Among the main lipid-soluble antioxidants are tochopherols (vitamin $\mathrm{E}$ ) and carotenoids (e.g. $\beta$-carotene), while among the water-soluble molecules are ROS scavenging enzymes [e.g. superoxide dismutases (SOD), ascorbate peroxidases (AP), other peroxidases, catalases, glutathione reductase (GR), glutathione peroxidases (GPx), glutathione transferases (GST), thioredoxin reductase (Trx R), glutaredoxin] and other molecules such as glutathione (GSH) and ascorbic acid

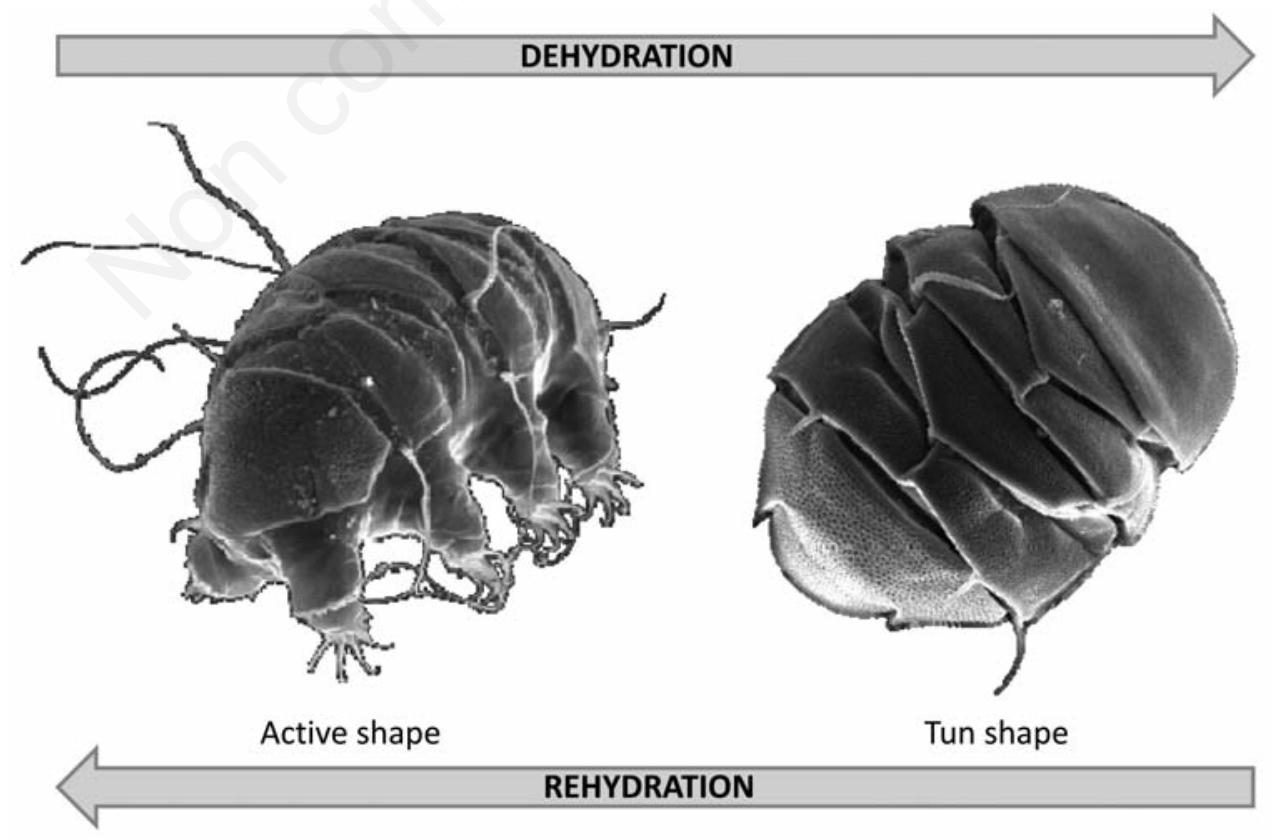

Fig. 1. Morphological body changes during the anhydrobiotic process in the heterotardigrade Echiniscus sp. In laboratory conditions, the process of desiccation lasts $24 \mathrm{~h}$ (Rebecchi et al., 2009b). At the end of this time, the animal reaches the tun shape and can maintain this physiological condition for months to decades. When drops of water are slowly added, the rehydration process takes place quickly. The desiccated animal absorbs the water rapidly and recovers its original active shape and mobility in about 30 min. 
(vitamin C) (Elstner and Osswald, 1994; Kranner and Birtić, 2005; França et al., 2007; Rebecchi et al., 2009a; Rizzo et al., 2010; Cornette and Kikawada, 2011). However, the enzymatic antioxidant reactions can occur only when a sufficient amount of water is available (e.g. during entrance and exit phases of anhydrobiosis).

These classical antioxidants are present in organisms from bacteria to humans, even though some of them may be absent in fungi and lower plants, and secondary products (e.g. phenolic products) with antioxidant properties are often contained in lichens and seeds. Other molecules with antioxidant properties are represented by flavonoids, sugars (e.g. trehalose), proline, polyamines and polyoils (Rice-Evan et al., 1996; Kranner and Birtić, 2005; França et al., 2007).

Many studies on evolutionarily distant organisms have shown that genes related to oxidative stress response are up-regulated during the desiccation process (Ingram and Bartels 1996; Browne et al., 2004; Oliver et al., 2004; Adhikari et al., 2009; Förster et al., 2009, 2012; Cornette et al., 2010; Gusev et al., 2010; Mali et al., 2010; Schokraie et al., 2010, 2012) and that tolerance to desiccation is correlated with an increase in the amount of antioxidant molecules and antioxidant activity (Figs. 2 and 3; Jiang and Zhang, 2002; Kranner and Birtić, 2005; França et al., 2007; Rizzo et al., 2010).

\section{Glutathione and glutathione reductase}

Glutathione and GSH-dependent enzymes represent a very important antioxidant system and an example of how antioxidants scavenge free radicals. The tripeptide GSH ( $\gamma$-Glu-Cys-Gly) functions as a ROS scavenger, but it also regulates the redox state within cells. At physiological pH, $\mathrm{GSH}$ is present as the glutathione anion $\left(\mathrm{GS}^{-}\right)$. Free radicals oxidize $\mathrm{GS}^{-}$to glutathione disulfide (GSSG), which is reduced to GSH at the expense of NADPH by the enzyme glutathione reductase (GR) (Kranner and Birtić, 2005; França et al., 2007). In this way, free radicals are scavenged, the antioxidant is restored and recycled, and the cell is protected from ROS. Consequently, anhydrobiosis is also correlated with the ability to restore the initial amount of GSH. The involvement of this antioxidant system in desiccation tolerant organisms has been described in bacteria, mosses, lichens, nematodes, tardigrades and chironomids (Kranner and Grill, 1996; Kranner and Birtić, 2005; França et al., 2007; Rizzo et al., 2010; Cornette et al., 2010; Cornette and Kikawada 2011). For example, in desiccated specimens of the tardigrade Paramacrobiotus richtersi (Murray 1911), the total amount of glutathione (Fig. 3) was significantly higher than that measured in hydrated animals, but the activity of glutathione reductase was not significantly higher in desiccated tardigrades compared to hydrated ones (Fig. 3; Rizzo et al., 2010).
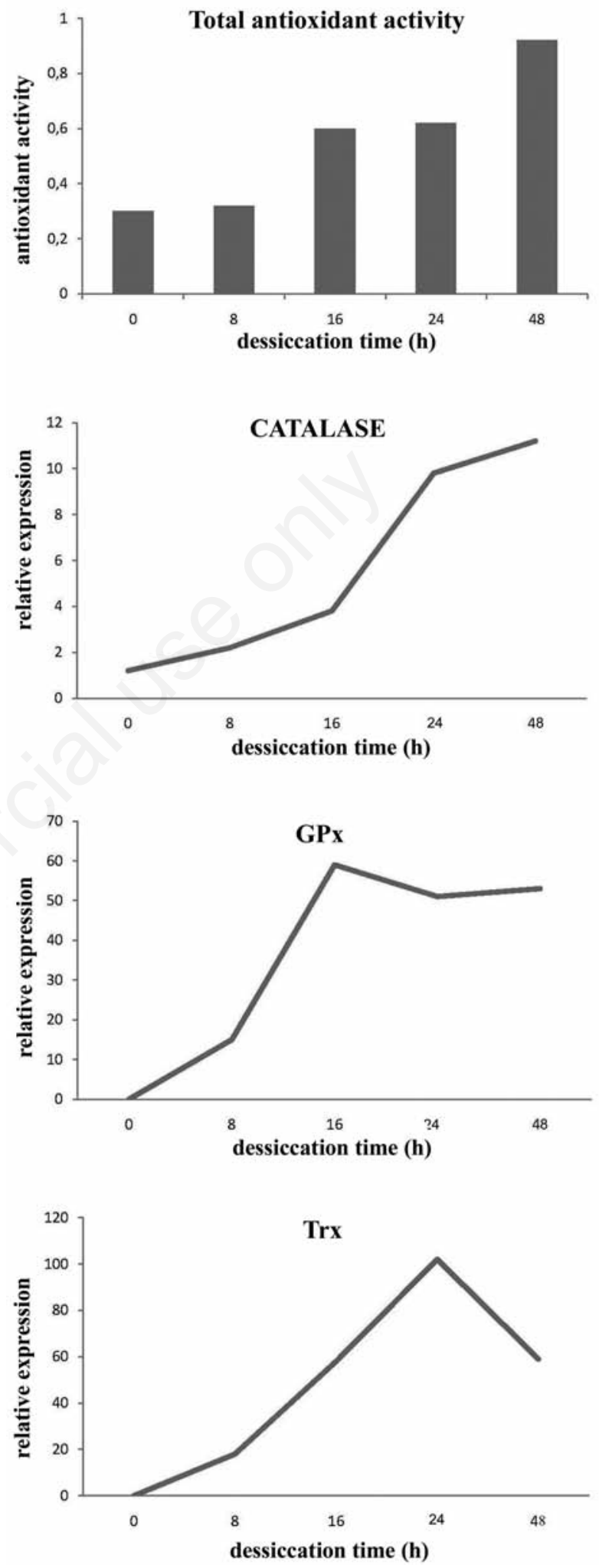

Fig. 2. Antioxidant defences in the chironomid Polypedilum vanderplanki larvae. The total antioxidant activity and the activity of the enzymes catalase, glutathione peroxidase (GPx) and thioredoxin (Trx) increase during desiccation. (Modified from Cornette and Kikawada, 2010). 

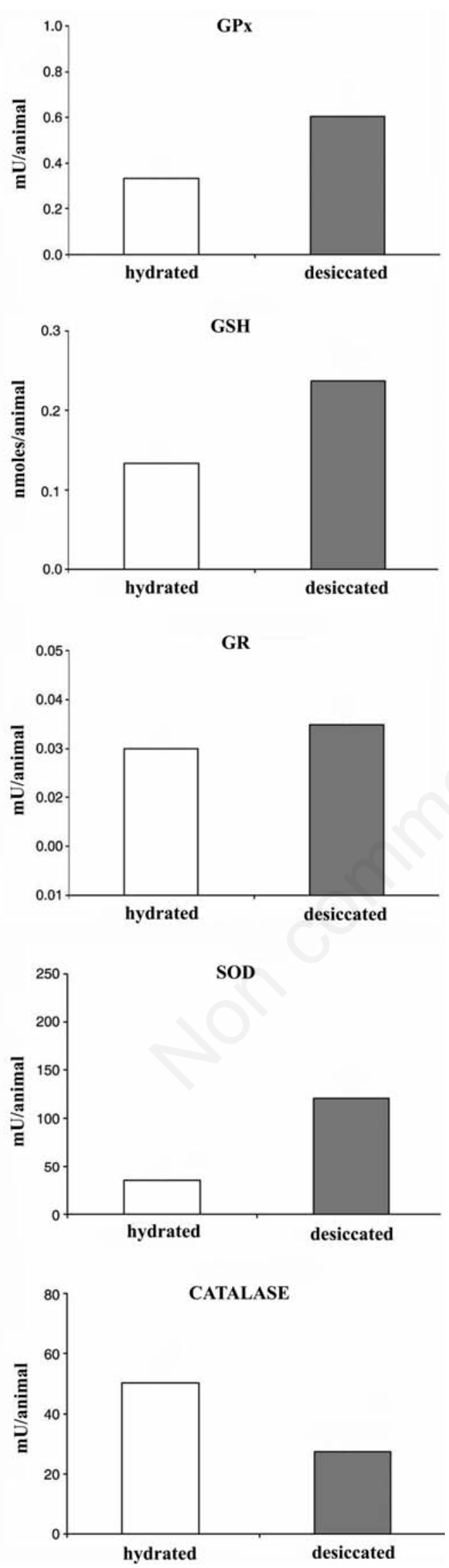

\section{Superoxide dismutase}

From microorganisms to humans, a primary defence utilised to counteract oxygen toxicity could involve the system of SOD and catalase enzymes. The four known groups of SODs destroy free radical superoxide by converting it into $\mathrm{H}_{2} \mathrm{O}_{2}$, which is reduced by catalase (Landis and Tower, 2005). In the cyanobacterium Nostoc commune Vaucher ex Bornet and Flahault, 1888, Fe-superoxide dismutase was the third most abundant soluble protein detected after 13 years of storage of the desiccated organisms (Shirkey et al., 2000). In desiccated specimens of the eutardigrade $P$. richtersi, the SOD activity increased more than 3-fold with respect to that of hydrated animals (Fig. 3; Rizzo et al., 2010). The analysis of the expressed sequence tags (ESTs) and proteome of the eutardigrade Milnesium tardigradum Doyère, 1840 resulted in the identification of 6 superoxide dismutases (Schokraie et al., 2010, 2012). Instead, in Polypedilum vanderplanki chironomid larvae, both mitochondrial (1 cluster) and cytosolic/extracellular (6 clusters) SODs were found (Cornette et al., 2010; Cornette and Kikawada, 2011).

\section{Catalase and glutathione peroxidase}

The primary defence mechanism against hydrogen peroxide $\left(\mathrm{H}_{2} \mathrm{O}_{2}\right)$ is catalase and GPx through the glutathione redox cycle. Catalase is one of the most efficient enzymes known; it is present in the peroxisomes fraction and reacts with $\mathrm{H}_{2} \mathrm{O}_{2}$, producing water and molecular oxygen $\left(\mathrm{O}_{2}\right)$ (Zamocky et al., 2008; Eruslanov and Kusmartsev, 2010). The synthesis of a catalase homolog found in the anhydrobiotic related EST database of $P$. vanderplanki was induced about 4-fold under desiccation (Fig. 2; Cornette et al., 2010; Cornette and Kikawada, 2011), whereas no differences in the catalase activity were detected between hydrated and desiccated specimens of $P$. richtersi (Fig. 3; Rizzo et al., 2010).

Similarly, the enzyme glutathione peroxidase (GPx) reduces $\mathrm{H}_{2} \mathrm{O}_{2}$, generated by SOD, to water oxidizing glutathione (Rizzo et al., 2007). In desiccated specimens of the tardigrade $P$. richtersi and the chironomid larvae $P$. vanderplanki, the GPx was the most abundant antioxidant

Fig. 3. Antioxidant defences in the eutardigrade Paramacrobiotus richtersi. The activity of glutathione peroxidase (GPx), glutathione reductase (GR) and superoxide dismutase (SOD) is higher in desiccated animals than in hydrated ones, while no differences were detected in the activity of the catalase between the two physiological states. The amount of glutathione (GSH) is significantly higher in desiccated tardigrades with respect to hydrated ones. (Modified from Rizzo et al., 2010). 
enzyme detected and its amount increased with desiccation (Figs. 2 and 3; Rizzo et al., 2010; Cornette et al., 2010; Cornette and Kikawada, 2011).

\section{Thioredoxin}

Thioredoxin (Trx) is another important enzyme against oxidative stress since it breaks down $\mathrm{H}_{2} \mathrm{O}_{2}$ to water. The importance of this enzyme in desiccation tolerance was first identified in the chironomid larvae P. vanderplanki, in which the activity of mitochondrial thioredoxin increased over 100-fold under desiccation stress (Fig. 2; Cornette et al., 2010; Conette and Kikawada, 2010). This is supported by the fact that mitochondria are the major site of ROS production and reduced thioredoxin can directly scavenge ROS (Corona and Robinson, 2006). In the eutardigrade $M$. tardigradum there are 14 thioredoxin-domains (Förster et al., 2009; Schokraie et al., 2010, 2012), even though no studies about their regulation during desiccation have been conducted.

\section{Trehalose}

The non-reducing disaccharide trehalose has been proposed to protect cells exposed to desiccation by replacing water at the surface of membranes (Crowe 1971, 1975; Crowe et al., 2005; Clegg, 2001), by forming amorphous glassy matrices that embed organelles and macromolecules (Wolkers et al., 2002), by preventing protein aggregation caused by heat shock (Singer and Lindquist, 1998), and by eliminating ROS (França et al., 2007). In yeast cells, Benaroudj et al. (2001) showed that trehalose is capable of reducing oxidant-induced alterations of proteins during exposure to $\mathrm{H}_{2} \mathrm{O}_{2}$, while Pereira et al. (2003) showed that this sugar is capable of reducing intracellular oxidation during dehydration, especially when cells contained a low amount of SOD. A further corroboration of the role of trehalose as an antioxidant comes from Oku et al. (2003). These authors showed that in vitro trehalose significantly reduced oxidation of unsaturated fatty acids through a weak interaction with the double bonds.

\section{Carotenoids}

Carotenoids are a large family of about 600 lipid-soluble pigments (red, orange, yellow) produced by photosynthesizing organisms. They are characterized by a long, linear main carbon chain with 11 conjugated $\mathrm{C}=\mathrm{C}$ double bonds that are responsible for the absorption of light in the visible region of the spectrum. In photosynthetic organisms, carotenoids are involved in the transfer of energy, and in the protection of reaction centers from auto-oxidation (Britton, 2008). Non-photosynthesizing organisms are incapable of synthesizing carotenoids de novo and animals must obtain them through their diet. Nevertheless, animals can metabolize carotenoids to different
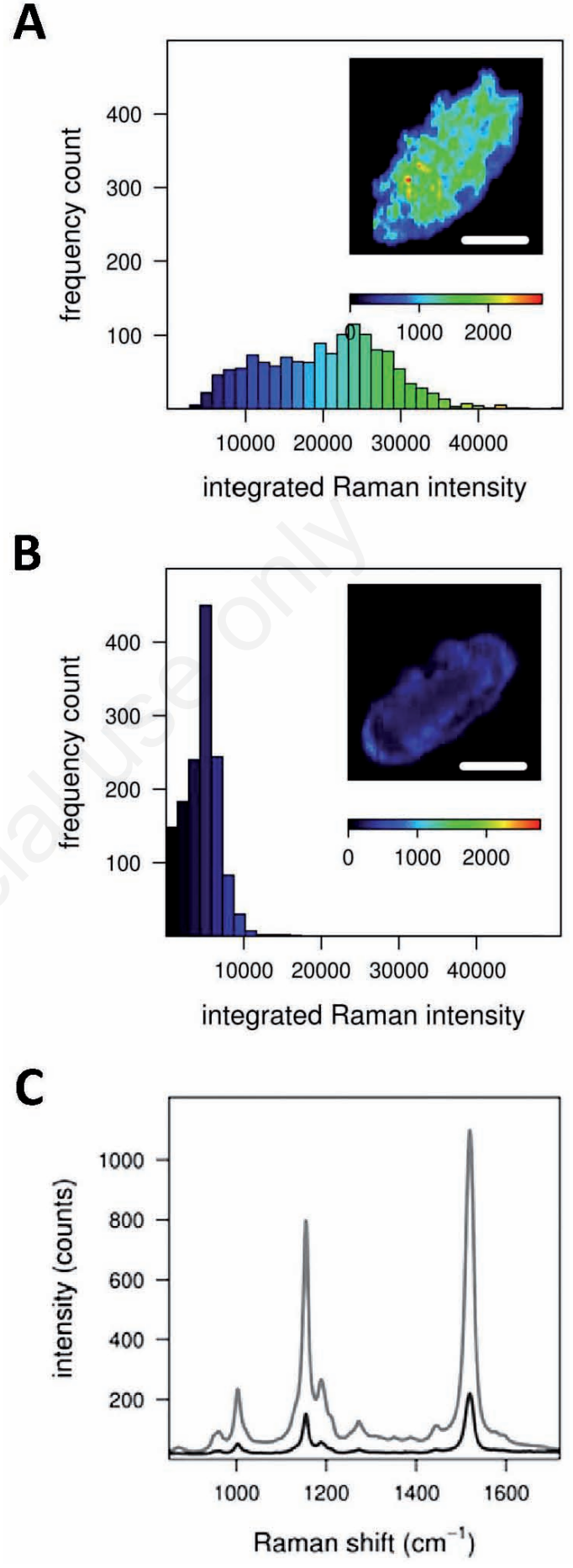

Fig. 4. Histograms of the integrated Raman intensity in the $1460-1570 \mathrm{~cm}^{-1}$ region (i.e. integral of the most intense band) from Raman maps of an Echiniscus blumi specimen before (A) and after (B) the treatment with hydrogen peroxide showing the decrease in carotenoid content. In each histogram, the corresponding intensity Raman map depicting the carotenoid distribution (i.e. the intensity at $1521 \mathrm{~cm}^{-1}$ ) is shown as inset. White scale bars $=200 \mu \mathrm{m}$, colour scale bars have units of counts. In C, average spectra of Raman maps before (grey) and after (black) the treatment. (Modified from Bonifacio et al., 2012). 
molecules such as products with retinoid activity (Bhosale and Bernstein, 2007). In animals, carotenoids have several functions, namely pigmentation with signalling purposes, immunity response, vision, nutrition of embryos, and protection against oxidative stress (Britton, 2008). In addition, because carotenoids absorb UV and violet-blue light, they can act also as light filters protecting animals against this harmful high-energy solar radiation, which is an indirect cause of oxidative damage generated by ROS (Britton, 2008). Even though terrestrial anhydrobiotic tardigrades show several kind of pigmentations (e.g. redorange, brown, green and yellow), their function (especially in relation to their resistance to harsh chemical and physical conditions) has not yet been determined. Recently, Bonifacio et al. (2012) showed a decrease in the amount of carotenoid (mainly $\beta$-carotene) after the induction of oxidative stress by $\mathrm{H}_{2} \mathrm{O}_{2}$ in the heterotardigrade Echiniscus blumi Richters, 1907 (Fig. 4). Consequently they proposed that carotenoids in tardigrades work as scavengers for ROS formed during exposure to dehydration and/or solar radiation.

\section{CONCLUSIONS}

An imbalance between the excessive production of ROS and the limited action of antioxidant defences could be responsible for the decrease in survival of organisms in the anhydrobiotic state. The antioxidant mechanisms must work in cooperation with other biochemical mechanisms and with physiological and morphological adaptations. Further studies are necessary to quantify the production of ROS in desiccated organisms, especially metazoans, as well on the proteome and metabolome of desiccated organisms to understand the basis of complete desiccation tolerance. The next challenge will be the ability to engineer complete desiccation tolerance in species of particular importance. For example, in the past two decades, the results coming from research on anhydrobiosis have been used to induce stress tolerance in human cells for medical purposes and to engineer desiccation tolerance in crop plants to make them less vulnerable to drought (Wolkers et al., 2002; Crowe et al., 2005; Potts et al., 2005).

\section{ACKNOWLEDGMENTS}

I thank Paulo Fontoura, Nuno Gomes Oliveira, Alexandre Valente and Cristina Neves for the organization of the Twelfth International Symposium on Tardigrada in Porto (Portugal). Their outstanding efforts allowed people that are fascinated by the biology of tardigrades to meet and exchange data and ideas, and to increase our knowledge on this neglected animal group. In addition, I would like to thank the Organizing Committee for giving me the honour to open the Twelfth International Symposium on Tardigrada.
I also thank K. Ingemar Jönsson and the other anonymous reviewers for their valuable comments and suggestions on the manuscript, and Diane R. Nelson for English revision of the text. This work is supported by the grants from the Italian Space Agency (ASI) for the project TARDIKISS (Tardigrades in Space), part of the BIOKIS project, a set of multidisciplinary experiments of DAMA mission.

\section{REFERENCES}

Adhikari BN, Wall DH, Adams BJ, 2009. Desiccation survival in an Antarctic nematode: molecular analysis using expressed sequenced tags. BMC Genomics 10:69.

Alpert P, 2005. The limits and frontiers of desiccation-tolerant life. Integr. Comp. Biol. 45:685-695.

Alpert P, 2006. Constraints of tolerance: why are desiccationtolerant organisms so small or so rare? J. Exp. Biol. 209:1575-1584.

Altiero T, Guidetti R, Caselli V, Cesari M, Rebecchi L, 2011. Ultraviolet radiation tolerance in hydrated and desiccated eutardigrades. J. Zool. Syst. Evol. Res. 49(Suppl. 1):98-103.

Bayley M, Holmstrup M. 1999. Water vapor absorption in arthropods by accumulation of myoinositol and glucose. Science 285:1909-1911.

Benaroudj N, Lee DH, Goldberg AL, 2001. Trehalose accumulation during cellular stress protects cells and cellular proteins from damage by oxygen radicals. J. Biol. Chem. 276:24261-24267.

Bhosale P, Bernstein PS, 2007. Vertebrate and invertebrate carotenoid-binding proteins. Arch. Biochem. Bioph. 458:121-127.

Billi D, Friedmann EI, Hofer KG, Grilli Caiola M, OcampoFriedmann R, 2000. Ionizing-radiation resistance in the desiccation-tolerant cyanobacterium Chroococcidiopsis. Appl. Environm. Microbiol. 66:1489-1492.

Billi D, Potts M, 2002. Life and death of dried prokaryotes. Res. Microbiol. 153:7-12.

Bonifacio A, Guidetti R, Altiero T, Sergo V, Rebecchi L, 2012. Nature, source and function of pigments in tardigrades: in vivo Raman imaging of carotenoids in Echiniscus blumi. PLoS ONE 7:e50162.

Boveris A, Chance B, 1973. The mitochondrial generation of hydrogen peroxide. General properties and effects of hyperbaric oxygen. Biochem. J. 134:707-716.

Britton G, 2008. Carotenoids, p. 189-212. In: G. Britton, S. Liaaen-Jensen, H. Pfander (eds.), Natural Functions. Birkhauser Verlag.

Browne JA, Dolan KM, Tyson T, Goyal K, Tunnacliffe A, Burnell AM, 2004. Dehydration-specific induction of hydrophilic protein genes in the anhydrobiotic nematode Aphelenchus avenae. Eukaryotic Cell 3:966-975.

Càceres CE, 1997. Dormancy in invertebrates. Invertebr. Biol. 116:371-383.

Clegg JS, 2001. Cryptobiosis - a peculiar state of biological organization. Comp. Biochem. Physiol. B 128:613-624.

Clegg JS, 2005. Desiccation tolerance in encsysted embryos of the animal extremophile, Artemia. Integr. Comp. Biochem. 45:715-724.

Cornette R, Kanamori M, Watanabe M, Nakahara Y, Gusev O, Mitsumasu K, Kadono-Okuda K, Shimomura M, Mita K, 
Kikawada T, Okuda T, 2010. Identification of anhydrobiosis-related genes from an expressed sequence tag database cryptobiotic midge Polypedilum vanderplanki (Diptera: Chironomidae). J. Biol. Chem. 285:35889-35899.

Cornette R, Kikawada T, 2011. The induction of anhydrobiosis in the sleeping chironomid: current status of our knowledge. IUBMB Life 63:419-429.

Corona M, Robinson GE, 2006. Genes of the antioxidant system of the honey bee: annotation and phylogeny. Insect Mol. Biol. 15:687-701.

Crowe JH, 1971. Anhydrobiosis: an unsolved problem. Am. Nat. 105:563-573.

Crowe JH, 1972. Evaporative water loss by tardigrades under controlled relative humidity. Biol. Bull. 142:407-416.

Crowe JH, 1975. The physiology of cryptobiosis in tardigrades. Mem. Ist. Ital. Idrobiol. 32:37-59.

Crowe JH, Crowe LM, Wolkers WF, Oliver AE, Ma X, Auh JH, Tang M, Zhu S, Norris J, Tablin F, 2005. Stabilization of dry mammalian cells: lessons from nature. Integr. Comp. Biol. 45:810-820.

Crowe JH, Hoekstra FA, Crowe LM, 1992. Anhydrobiosis. Ann. Rev. Physiol. 54:579-599.

Cruz de Carvalho R, Català M, Marques da Silva G, Branquinho C, Barreno E, 2012. The impact of dehydration on the production and cellular location of reactive oxygen species in an aquatic moss. Ann. Bot. 110:1007-1016.

Danks HV, 2000. Dehydration in dormant insect. J. Insect Physiol. 46:837-852.

Elstner EF, Osswald W, 1994. Mechanisms of oxygen activation during plant stress. Proc. Roy. Soc. Edinburgh 102:131-154.

Eruslanov E, Kusmartsev S, 2010. Identification of ROS using oxidized DCFDA and flow-cytometry. Meth. Mol. Biol. 594:57-72.

Faurby S, Jönsson KI, Rebecchi L, Funch P, 2008. Variation in anhydrobiotic survival of two eutardigrade morphospecies: a story of cryptic species and their dispersal. J. Zool. 275:139-145.

França MB, Panek AD, Eleutherio ECA, 2007. Oxidative stress and its effects during dehydration. Comp. Biochem. Physiol. A 146:621-631.

Förster F, Beisser D, Grohme MA, Liang C, Mali B, Sieg AM, Engelmann JC, Shkumatov AV, Schokraie E, Müller T, Schnölzer M, Schill RO, Frohme M, Dandekar T, 2012. Transcriptome analysis in tardigrade species reveals specific molecular pathways for stress adaptations. Bioinf. Biol. Ins. 2012:669-696.

Förster F, Liang C, Shkumatov A, Beisser D, Engelmann JC, Schnolzer M, Frohme M, Muller T, Schill RO, Dandekar T, 2009. Tardigrade workbench: comparing stress-related proteins, sequence-similar and functional protein clusters as well as RNA elements in tardigrades. BMC Genomics 10:469.

Giard A, 1894. [L'anhydrobiose ou ralentissement des phénomènes vitaux]. [Article in French]. C. R. Soc. Biol. Paris 46:497-500.

Gladyshev E, Meselson M, 2008. Extreme resistance of bdelloid rotifers to ionizing radiation. PNAS 105:5139-5144.

Goyal K, Walton LJ, Browne JA, Burnell AM, Tunnacliffe A, 2005a. Molecular anhydrobiosis: identifying molecules implicated in invertebrate anhydrobiosis. Integr. Comp. Biol. 45:702-709.
Guidetti R, Altiero T, Rebecchi L, 2011. On dormancy strategies in tardigrades. J. Insect Physiol. 57:567-576.

Gusev O, Nakakara Y, Vanyagina V, Malutina L, Cornette R, Sakashita T, Hamada N, Kikawada T, Kobayashi Y, Okuda T, 2010. Anhydrobios-associated nuclear DNA damage and repair in the sleeping chironomid: linkage with radioresistance. PLoS One 5:114008.

Haegeman A, Jacob J, Vanholme B, Kyndt T, Mitreva M, Gheysen $G, 2009$. Expressed sequence tags of the peanut pod nematode Ditylenchus africanus: the first transcriptome analysis of an anguinid nematode. Mol. Biol. Parasitol. 167:32-40.

Hansen JM, Go YM, Jones DP, 2006. Nuclear and mitochondrial compartmentation of oxidative stress and redox signaling. Annu. Rev. Pharmacol. Toxicol. 46:215-234.

Hengherr S, Brünner F, Schill RO, 2008. Anhydrobiosis in tardigrades and its effects on longevity traits. J. Zool. 275:216220.

Hengherr S, Worland MR, Reuner A, Brümmer F, Schill RO, 2009a. Freeze tolerance, supercooling points and ice formation: comparative studies on the subzero temperature survival of limno-terrestrial tardigrades. J. Exp. Biol. 212:802-807.

Hengherr S, Worland MR, Reuner A, Brümmer F, Schill RO, 2009b. High-temperature tolerance in anhydrobiotic tardigrades is limited by glass transition. Physiol. Biochem. Zool. 82:749-755.

Horikawa DD, Iwata KI, Kawai K, Kosek S, Okuda T, Yamamoto K, 2009. High hydrostatic pressure tolerance of four different anhydrobiotic animal species. Zool. Sci. 26:238-242.

Illing N, Denby KJ, Collett H, Shen A, Farrant JM, 2005. The signature of seeds in resurrection plants. A molecular and physiological comparison of desiccation tolerance in seeds and vegetative tissues. Integr. Comp. Biol. 45:771-787.

Ingram J, Bartels D, 1996. The molecular basis of dehydration tolerance in plants. Annu. Rev. Plant Physiol. Plant Mol. Biol. 47:377-403.

Jiang M, Zhang J, 2002. Water stress-induced abscisic acid accumulation triggers the increased generation of reactive oxygen species and up-regulates the activities of antioxidant enzymes in maize leaves. J. Exp. Bot. 53:2401-2410.

Jönsson KI, 2005. The evolution of life histories in holo-anhydrobiotic animals: a first approach. Integr. Comp. Biol. 45:764-770.

Jönsson KI, Borsari S, Rebecchi L, 2001. Anhydrobiotic survival in populations of the tardigrades Richtersius coronifer and Ramazzottius oberhaeuseri from Italy and Sweden. Zool. Anz. 240:419-423.

Jönsson KI, Rabbow E, Schill RO, Harms-Ringdahl M, Rettberg P, 2008. Tardigrades survive exposure to space in Low Earth Orbit. Curr. Biol. 18:729-731.

Keilin D, 1959. The problem of anabiosis or latent life: history and current concepts. Proc. Roy. Soc. B 150:149-191.

Kranner I, Birtić S, 2005. A modulating role for antioxidant in desiccation tolerance. Integr. Comp. Biol. 45:734-740.

Kranner I, Grill D, 1996. Significance of thiol-disulphide exchange in resting stage of plant development. Bot. Acta 109:8-14.

Landis GN, Tower J, 2005. Superoxide dismutase evolution and 
life span regulation. Mech. Ageing Dev. 126:365-379.

Mali B, Grohme MA, Förster F, Dandekar T, Schnölzer M, Reuter D, Wełnicz W, Schill RO, Frohme M, 2010. Transcriptome survey of the anhydrobiotic tardigrade Milnesium tardigradum in comparison with Hypsibius dujardini and Richtersius coronifer. BMC Genomics 11:168.

Marotta R, Leasi F, Uggetti A, Ricci C, Melone G, 2010. Dry and survive: morphological changes during anhydrobiosis in a bdelloid rotifer. J. Struct. Biol. 171:11-17.

Mattimore V, Battista JR, 1996. Radioresistance of Deinococcus radiodurans: functions necessary to survive ionizing radiation are also necessary to survive prolonged desiccation. J. Bacteriol. 178:633-637.

Møbjerg N., Halberg KA, Jørgensen A, Persson D, Bjørn M, Ramløv H, Kristensen RM, 2011. Survival in extreme environments: on the current knowledge of adaptations in tardigrades. Acta Physiol. 202:409-420.

Neumann S, Reuner A, Brünner F, Schill RO, 2009. DNA damage in storage cells of anhydrobiotic tardigrades. Comp. Biochem. Physiol. A 153:425-429.

Nilsson EJC, Jönsson KI, Pallon J, 2010. Tolerance to proton irradiation in the eutardigrade Richtersius coronifer: a nuclear microprobe study. Int. J. Rad. Biol. 86:420-427.

Oku K, Watanabe H, Kubota M, Fukuda S, Kurimoto M, Tsujisaka Y, Komori M, Inoue Y, Sakurai M, 2003. NMR and quantum chemical study on the $\mathrm{OH}$...pi and $\mathrm{CH}$... O interactions between trehalose and unsaturated fatty acids: implication for the mechanism of antioxidant function of trehalose. J. Am. Chem. Soc. 125:12739-12748.

Oliver MJ, Dowd SE, Zaragoza J, Mauget SA, Payton PR, 2004. The rehydration transcriptome of the desiccation-tolerant bryophyte Tortula ruralis: transcript classification and analysis. BMC Genomics 5:89.

Oliver MJ, Tuba Z, Mishler BD, 2000. The evolution of vegetative desiccation tolerance in land plants. Plant Ecol. 151:85100.

Pereira EJ, Panek AD, Eleutherio ECA, 2003. Protection against oxidation during dehydration of yeast. Cell Stress Chaperones 8:120-124.

Potts M, 1994. Desiccation tolerance of prokaryotes. Microbiol. Rev. 58:755-805.

Potts M, Slaugheter SM, Hunneke F-U, Garst JF, Helm R, 2005. Desiccation tolerance of prokaryotes: application of principles to human cells. Integr. Comp. Biol. 45:800-809.

Price AH, Atherton NM, Hendry GAF, 1989. Plants under drought stress generate activated oxygen. Free Radic. Res. Commun. 8:61-66.

Rebecchi L, Altiero T, Cesari M, Bertolani R, Rizzo AM, Corsetto P, Guidetti R, 2011. Resistance of the anhydrobiotic eutardigrade Paramacrobiotus richtersi to space flight (LIFE-TARSE mission on FOTON-M3). J. Zool. Syst. Evol. Res. 49(Suppl. 1):98-103.

Rebecchi L, Altiero T, Guidetti R, 2007. Anhydrobiosis: the extreme limit of desiccation tolerance. Invertebr. Surv. J. 4:65-81.

Rebecchi L, Altiero T, Guidetti R, Cesari M, Bertolani R, Negroni M, Rizzo AM, 2009a. Tardigrade resistance to space effects: first results of experiments on the LIFE - TARSE Mission on FOTON-M3 (September 2007). Astrobiology 9:581-591.
Rebecchi L, Cesari M, Altiero T, Frigieri A, Guidetti R, 2009 b. Survival and DNA degradation in anhydrobiotic tardigrades. J. Exp. Biol. 212:4033-4039.

Rebecchi L, Guidetti R, Borsari S, Altiero T, Bertolani R, 2006. Dynamics of long-term anhydrobiotic survival of lichendwelling tardigrades. Hydrobiologia 558:23-30.

Rice-Evans CA, Miller Nj, Paganga G, 1996. Structure antioxidant activity relationship of flavonoids and phenolic acids. Free Rad. Biol. Med. 20:933-956.

Ricci C, 1998. Anhydrobiotic capability of bdelloid rotifers. Hydrobiologia 387/388:321-326.

Ricci C, 2001. Dormancy patterns in rotifers. Hydrobiologia 446/447:1-11.

Ricci C, Caprioli M, 2005. Anhydrobiosis in bdelloid species, populations and individuals. Integr. Comp. Biol. 45:759763.

Rizzo AM, Adorni L, Montorfano G, Rossi F, Berra B, 2007. Antioxidant metabolism of Xenopus leavis embryos the first days of development. Comp. Biochem. Physiol. B 156:94100 .

Rizzo AM, Negroni M, Altiero T, Montorfano G, Corsetto P, Berselli P, Berra B, Guidetti R, Rebecchi L, 2010. Antioxidant defences in hydrated and desiccated states of the tardigrade Paramacrobiotus richtersi. Comp. Biochem. Physiol. B 156:115-121.

Schill RO, 2010. Anhydrobiotic abilities of tardigrades. In: E. Lubzens, J. Cerdà and M.S. Clark (eds.), Dormancy and Resistance in Harsh Environments. Topics in Current Genetics. Springer-Verlag Berlin Heidelberg. 21:133-146.

Schokraie E, Hotz-Wagenblatt A, Warnken U, Mali B, Frohme M, Förster F, Dandekar T, Hengherr S, Schill RO, Schnölzer M, 2010. Proteomic analysis of tardigrades: towards a better understanding of molecular mechanisms by anhydrobiotic organisms. PLoS One 5:e9502.

Schokraie E, Warnken U, Hotz-Wagenblatt A, Grohme M, Hengherr S, Förster F, Schill RO, Frohme M, Dandekar T, Schnölzer M, 2012. Comparative proteome analysis of Milnesium tardigradum in early embryonic state versus adults in active and anhydrobiotic state. PLoS One 7:e45682.

Shirkey B, Kovarcik DP, Wright DJ, Wilmoth G, Pricket TF, Helm RF, Gregory EM, Potts M, 2000. Active Fe-containing superoxide dismutase and abundant sodf mRNA in Nostoc commune (Cyanobacteria) after years of desiccation. J. Bacteriol. 182:189-197.

Singer MA, Lindquist S. 1998. Thermotolerance in Saccharomyces cerevisiae - the yin and yang of trehalose. Trends Biotechnol. 16:460-468.

Smirnoff N, 1993. Role of active oxygen in the response of plants to water deficits and desiccation. New Phytol. 125:2758.

Sun WQ, Leopold AC, 1997. Cytoplasmic vitrification and survival of anhydrobiotic organisms. Comp. Biochm. Physiol. A 117:327-333.

Tunnacliffe A, Lapinski J, 2003. Resurrecting Van Leeuwenhoek's rotifers: a reappraisal of the role of disaccharides in anhydrobiosis. Phil. Trans. R. Soc. London B 358:17551771.

Tweddle JC, Dickie JB, Baskin CC, Baskin JM, 2003. Ecological aspects of seed desiccation sensitivity. J. Ecol. 91:294304. 
Van Leeuwenhoek A, 1702. On certain animalcules found in the sediments in gutter of the roofs of houses. Letter 144 to Hendrik van Bleyswijk, dated 9 February 1702, p. 207-213. In: The select works of Anton van Leeuwenhoek. 2. G. Sidney Publisher.

Watanabe M, 2006. Anhydrobiosis in invertebrates. Appl. Entomol. Zool. 41:15-31.

Watanabe M, Nakahara Y, Sakashita T, Kikawada T, Fujita A, Hamada N, Horikawa DD, Wada S, Kobayashi Y, Okuda T, 2007. Physiological changes leading to anhydrobiosis improve radiation tolerance in Polypedilum vanderplanki larvae. J. Insect Physiol. 53:573-579.

Wełnicz W, Grohme MA, Kaczmarek Ł, Schill RO, Frohme M. 2011. Anhydrobiosis in tardigrades: The last decade. J. Insect Physiol. 57:577-583.

Willcox JK, Ash SL, Catignani GL, 2004. Antioxidants and prevention of chronic disease. Crit. Rev. Food Sci. Nutr. 44:275-295.

Wojtasezek P, 1997. Oxidative burst: an early response to pathogen degradation. Biochem. J. 322:681-692.

Wolkers WF, Tablin F, Crowe JH. 2002. From anhydrobiosis to freeze-drying of eukaryotic cells. Comp. Biochem. Physiol. A 131:535-543.

Wright JC, 1988. Structural correlates of permeability and tun formation in tardigrade cuticle: an image analysis study. J. Exp. Ultrastruct. Mol. Res. 101:23-29.

Wright JC, 1989a. The tardigrade cuticle II. Evidence for a dehydration-dependent permeability barrier in the cuticle. Tissue \& Cell 21:263-279.

Wright JC, 1989b. Desiccation tolerance and water-retentive mechanisms in tardigrades. J. Exp. Biol. 142:267-292.

Wright JC, 2001. Cryptobiosis 300 Years on from van Leeuwenhoek: what have we learned about tardigrades? Zool. Anz. 240:563-582.

Zamocky M, Fürtmuller PG, Obinger C, 2008. Evolution of catalases from bacteria to humans. Antioxidants \& Redox Signal 10:1527-1547. 